FORSCHUNG - AUSBILDUNG - WEITERBILDUNG

Bericht Nr. 72

A MATHEMATICAL MODEL FOR DIFFUSION AND

EXCHANGE PHENOMENA IN ULTRA NAPKINS

Joachim Weickert

UNIVERSITÄT KAISERSLAUTERN

Fachbereich Mathematik

Arbeitsgruppe Technomathematik

Postfach 3049

W-6750 Kaiserslautern

Juni 1992 


\title{
A MATHEMATICAL MODEL FOR DIFFUSION AND \\ EXCHANGE PHENOMENA IN ULTRA NAPKINS
}

\author{
JOACHIM WEICKERT \\ University of Kaiserslautern \\ Laboratory of Technomathematics \\ P.O. Box 3049 \\ $D-W-6750$ Kaiserslautern \\ Germany \\ Tel.: $\quad++496312054084$ \\ Fax: $\quad++496312053052$ \\ e-mail: weickert at mathematik.uni-kl.de
}

MSC Classification (1991): 35K20, 35K55, 35K57, 35K60, 65M06.

\begin{abstract}
.
The performance of napkins is nowadays improved substantially by embedding granules of a superabsorbent into the cellulose matrix. In this paper a continuous model for the liquid transport in such an "Ultra napkin" is proposed. Its mean feature is a nonlinear diffusion equation strongly coupled with an ODE describing a reversible absorbtion process. An efficient numerical method based on a symmetrical time splitting and a finite difference scheme of ADI-predictor-corrector type has been developed to solve these equations in a three dimensional setting. Numerical results are presented that can be used to optimize the granule distribution.
\end{abstract}




\section{CONTENTS}

1. Introduction 1

2. The Mathematical Model 2

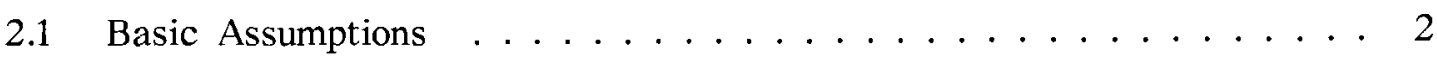

2.2 Liquid Transport in the Cellulose ................ 3

2.2.1 Derivation of the Diffusion Equation $\ldots \ldots \ldots 3$

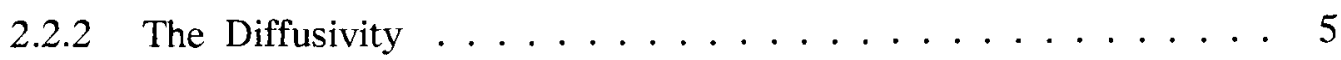

2.3 Liquid Exchange between Cellulose and Granules . . . . . . . . 6

2.4 The Mathematical Model .................... 8

3. Numerical Approximation 11

3.1 Time Splitting . . . . . . . . . . . . . . . . . 11

3.2 Analytical Solution of the Exchange Equation ........... 12

3.3 Numerical Approximation of the Diffusion Equation . . . . . . . 13

3.4 Time Step Size Control . . . . . . . . . . . . . . 16

3.5 The Computer Programme . . . . . . . . . . . . . . 17

4. Application to Real-Life Problems 19

4.1 Investigation of Current Napkins . . . . . . . . . . . . . . 19

4.2 Suggestions for Improved Napkins . . . . . . . . . . . . . . 22

5. Summary and Conclusions 27

$\begin{array}{lrr}\text { 6. } & \text { References } & 28\end{array}$ 


\section{INTRODUCTION}

Ultra napkins consist of cellulose with embedded little granules of a superabsorbent (Fig. 1). These granules are able to absorb an amount of liquid which reaches up to 65 times their own weight [1]. During this process they become a gel and their volume increases drastically (Fig. 2). Since the baby is not sensible of liquid inside the granules, this technique helps to keep it dry.
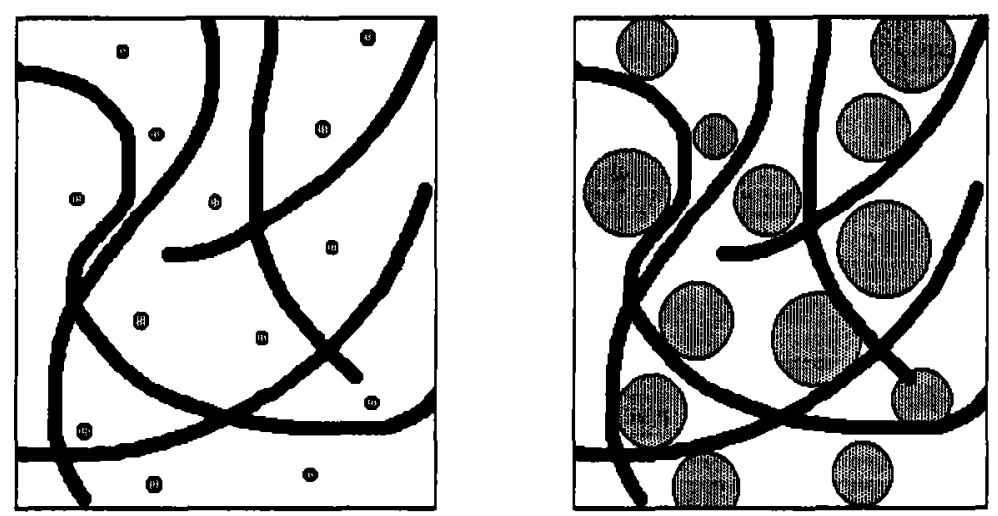

Fig. 1 (left).

Ultra napkin before liquid absorbtion

Fig. 2 (right)

Ultra napkin after liquid absorbtion

A substantial complication arises from the fact that the expanded granule volume hinders further liquid transport in the cellulose. It may occur that the napkin is locally saturated, while still being able to absorb much liquid elsewhere. This phenomenon is called gluing effect or gel blocking.

Consequently, the problem of optimizing the distribution of the granules in the napkin arises. An appropriate mathematical model could help the producers to improve their napkins in order to minimize gluing effects by means of an inhomogeneous granule distribution instead of the usual homogeneous one.

The present report is concerned with this topic and organized as follows.

In section 2 a mathematical model for liquid absorbtion and transport in a cellulosegel composite is derived. It leads to a nonlinear diffusion equation (for the transport in the cellulose) strongly coupled with an ordinary differential equation (for the liquid exchange between cellulose and granules). Section 3 deals with a fast numerical solver for these equations. A symmetrical time splitting is used which has the advantage that either pure diffusion or pure exchange processes have to be considered in one step. The exchange equation can be solved analytically, while for the diffusion equation a finite difference method of ADI-predictor-corrector type is used. In section 4 our computer simulation is applied to real-life problems: the behaviour of different types of napkins is analyzed and it is demonstated how napkins can be improved by using a suitable inhomogeneous granule distribution. 


\section{THE MATHEMATICAL MODEL}

\subsection{Basic Assumptions}

To end up with a mathematical model which is not too complicated several effects must be neglected. We make the following assumptions.

a) The napkin consists exclusively of cellulose and granules. The granules can only store liquid, but they cannot transport it, while cellulose is supposed to exhibit both transport and storage properties. Therefore we have to be concerned with a liquid transport in the cellulose and an exchange of liquid between granules and cellulose.

b) Cellulose consists of fibres and intermediate spaces. Liquid is transported in the intermediate spaces and cannot pour into the fibres. In the present report we consider a homogeneous cellulose density and we assume the material to be isotropic.

c) The granule volume is equal to the volume of the absorbed liquid. This means that the initial volume of the granules without liquid is negligible and the liquid volume is not altered due to the absorbtion process.

If the granules absorb liquid, then their increasing volume is completely compensated by a decrease of the intermediate spaces at the same place. So inner deformations caused by a change of the granule volume do not influence the napkin's shape.

d) We do not take into account outer deformations due to the weigth or motion of the baby. Therefore the napkin keeps the same shape for all times.

e) Temperature and gravitation effects are neglected. 


\subsection{Liquid Transport in the Cellulose}

\subsubsection{Derivation of the Diffusion Equation}

In order to describe the liquid transport in the cellulose we choose a model like in mass diffusion or heat transfer. For this we need to introduce some notations.

\begin{tabular}{|c|c|c|c|}
\hline \multicolumn{3}{|l|}{$\mathbf{x}$} & space \\
\hline \multicolumn{3}{|l|}{$\mathrm{t}$} & time \\
\hline \multicolumn{3}{|l|}{$\mathbf{v}(\mathbf{x}, \mathrm{t})$} & velocity field \\
\hline \multicolumn{3}{|l|}{$\mathrm{u}_{\mathrm{c}}$} & liquid (urine) mass in the cellulose \\
\hline \multicolumn{3}{|l|}{$\mathrm{V}$} & volume \\
\hline \multicolumn{3}{|l|}{$\mathrm{V}_{\mathrm{I}}$} & volume of the intermediate spaces \\
\hline$c_{C}(x, t)$ & $:=$ & $\frac{\mathrm{du}_{\mathrm{C}}}{\mathrm{dV}}(\mathbf{x}, \mathrm{t})$ & liquid concentration in the cellulose \\
\hline$\tilde{c}_{\mathrm{C}}(\mathbf{x}, \mathbf{t})$ & & $\frac{d u_{C}}{d V_{I}}(x, t)$ & intermediate space saturation \\
\hline$\tilde{\mathbf{j}}(\mathbf{x}, \mathbf{t})$ & $:=$ & $\mathbf{v}(\mathbf{x}, \mathrm{t}) \cdot \tilde{c}_{\mathrm{C}}(\mathbf{x}, \mathrm{t})$ & $\begin{array}{l}\text { flux density related to the interme- } \\
\text { diate spaces }\end{array}$ \\
\hline
\end{tabular}

One essential property of diffusion is the fact that concentation differences are equalized. This behaviour is decribed by Fick's law

$$
\tilde{\mathbf{j}}(\mathbf{x}, \mathrm{t})=-\mathrm{d}\left(\tilde{\mathbf{c}}_{\mathrm{c}}(\mathbf{x}, \mathrm{t})\right) \cdot \operatorname{grad}\left(\tilde{\mathbf{c}}_{\mathrm{c}}(\mathbf{x}, \mathrm{t})\right) .
$$

Due to (2.1) concentration differences create a flux in the direction of the steepest concentration descent (for isotropic media). Since the transport takes place in the intermediate spaces, it has to be related to the intermediate space volume. In the present model the diffusivity $d$ is a function of the saturation in the intermediate spaces. A proposal for this dependance is given in the next section.

The second important feature of diffusion is the property that it does not generate or destroy mass. Hence the rate of change of the total mass in an arbitrary, but fixed volume is given by the flux through the surface. This is just the integral formulation of the continuity equation. The corresponding differential description is given by

$$
\frac{\partial \mathrm{c}_{\mathrm{C}}}{\partial \mathrm{t}}(\mathbf{x}, \mathrm{t})+\operatorname{div}\left(\mathbf{v}(\mathbf{x}, \mathrm{t}) \cdot \mathrm{c}_{\mathrm{C}}(\mathbf{x}, \mathrm{t})\right)=0
$$


Using the chain rule

$$
c_{C}(\mathbf{x}, t)=\frac{d V_{I}}{d V}(\mathbf{x}, t) \cdot \tilde{c}_{c}(\mathbf{x}, t)
$$

we can plug Fick's law into the continuity equation and end up with the diffusion equation

$$
\frac{\partial c_{C}}{\partial t}(\mathbf{x}, t)=\operatorname{div}\left(\frac{d V_{I}}{d V}(x, t) \cdot d\left(\tilde{c}_{C}(x, t)\right) \cdot \operatorname{grad}\left(\tilde{c}_{C}(x, t)\right)\right) .
$$

In (2.4) two types of concentrations occur: $c_{C}$ (which is related to the total volume) and $\tilde{c}_{\mathrm{C}}$ (which is related to the intermediate space volume). The connection between these two is given by (2.3).

Physically, it is reasonable to assume that $d V_{I} / d V>0$. This quantity can be expressed by the liquid concentration in the granules according to

$$
\begin{aligned}
& \frac{d V_{I}}{d V}(\mathbf{x}, t)=1-\frac{\rho_{C}}{\rho_{F}}-\frac{c_{G}(\mathbf{x}, t)}{\rho_{U}} \\
& \left(\begin{array}{l}
\text { intermediate } \\
\text { space volume }
\end{array}\right)=\left(\begin{array}{l}
\text { total } \\
\text { volume }
\end{array}\right)-\left(\begin{array}{l}
\text { volume of } \\
\text { the fibres }
\end{array}\right)-\left(\begin{array}{l}
\text { volume of the liquid } \\
\text { in the granules }
\end{array}\right) \\
& \text { with } \rho_{\mathrm{C}} \quad \text { density of the cellulose } \\
& \rho_{F} \quad \text { density of the cellulose fibres } \\
& \rho_{\mathrm{U}} \quad \text { density of the urine } \\
& \mathrm{u}_{\mathrm{G}} \quad \text { urine mass in the granules } \\
& c_{G}(x, t):=\frac{d_{u_{G}}}{d V}(x, t) \quad \text { liquid concentration in the granules. }
\end{aligned}
$$

From (2.3) and (2.5) we obtain the transformation

$$
\tilde{\mathbf{c}}_{\mathrm{C}}(\mathbf{x}, \mathrm{t})=\frac{\mathrm{c}_{\mathrm{C}}(\mathbf{x}, \mathrm{t})}{1-\frac{\rho_{\mathrm{C}}}{\rho_{\mathbf{F}}}-\frac{\mathrm{c}_{\mathrm{G}}(\mathbf{x}, \mathrm{t})}{\rho_{\mathrm{U}}}}
$$




\subsubsection{The Diffusivity}

This section presents a heuristical model for the dependence of the diffusivity on the intermediate space saturation.

For a given concentration $\tilde{c_{C}}$ the fraction $\tilde{c_{C}} / \rho_{U}$ of the intermediate spaces is filled with liquid. If the liquid is assumed to be an ideal fluid, then liquid particles can be transported in the interior without friction.

Their transport is hindered at those places where no liquid is present, which applies to the fraction $1-\tilde{c_{C}} / \rho_{U}$ of the intermediate spaces. Here the liquid particles have to overcome adhesion forces at the surface of the fibres. We will interpret these forces as a potential barrier. To overcome this barrier each particle needs a minimal energy $E_{A}$. We suppose

$$
\mathrm{E}_{\mathrm{A}} \sim 1-\frac{\tilde{\mathrm{c}_{\mathrm{C}}}}{\rho_{\mathrm{U}}}
$$

Furthermore, the particles are assumed to obey a Maxwell-Boltzmann distribution. So for a fixed temperature the fraction of particles with an energy larger than $E_{A}$ is proportional to $\exp \left(-\eta \mathrm{E}_{\mathrm{A}}\right)$ with a positive constant $\eta$.

Since we know from Fick's law that for a given concentration gradient the diffusivity is proportional to the flux through a fixed surface, we can summarize our considerations by

$$
\begin{aligned}
& \mathrm{d}\left(\tilde{\mathrm{c}}_{\mathrm{C}}\right) \sim \exp \left(-\eta \cdot \mathrm{E}_{\mathrm{A}}\right)=\exp \left(-\xi \cdot\left(1-\frac{\tilde{\mathrm{c}}_{\mathrm{C}}}{\rho_{\mathrm{U}}}\right)\right) \sim \exp \left(\beta \cdot \tilde{\mathrm{c}}_{\mathrm{C}}\right) \\
& \text { with } \eta, \xi, \beta>0 .
\end{aligned}
$$

Therefore it is justified to choose an ansatz of the type

$$
\mathrm{d}\left(\widetilde{\mathrm{c}_{\mathrm{C}}}\right)=\mathrm{d}_{0} \cdot \exp \left(\beta \cdot \widetilde{\mathrm{c}_{\mathrm{C}}}\right) \quad \text { with } \mathrm{d}_{0}, \beta>0
$$

Note: The diffusivity increases with growing liquid concentration in the intermediate spaces. This behaviour is not unusual, see e.g. [3].

The reader who is surprised by this can think of two flower pots, one with dry ground, the other with humid ground. If we put some liquid in both pots the equalization of the concentrations will be faster in the humid pot.

However, this does not mean that a wet napkin shows better transport properties than a dry one. The reason is that a wet napkin usually exhibits smaller concentration differences. 


\subsection{Liquid Exchange between Cellulose and Granules}

This section deals with the storage properties of granules and cellulose.

Because of physical effects cellulose has the property to attach liquid particles on the surface of its fibres. This effect is supposed to be proportional to the fibres' surface. If we assume that the cellulose density has a negligible influence on the bedewable fibre surface and that there exists a characteristic fibre shape, then this affinity is proportional to the cellulose mass. So we may write

$$
\begin{aligned}
& \mathrm{u}_{\mathrm{CA}}=\eta_{\mathrm{c}} \cdot \mathrm{m}_{\mathrm{C}} \\
& \text { with } \quad \mathrm{m}_{\mathrm{C}} \quad \text { mass of the cellulose } \\
& \mathbf{u}_{\mathrm{CA}} \quad \text { maximal liquid mass absorbable by the cellulose } \\
& \eta_{\mathrm{C}} \quad \text { affinity factor of the cellulose }\left(\eta_{\mathrm{C}}>0\right) \text {. }
\end{aligned}
$$

For the granules a similiar formula can be justified [1]:

$$
\begin{array}{lll}
\mathrm{u}_{\mathrm{GA}}=\eta_{\mathrm{G}} \cdot \mathrm{m}_{\mathrm{G}} & \\
\text { with } & \mathrm{m}_{\mathrm{G}} & \text { mass of the granules } \\
& \mathrm{u}_{\mathrm{GA}} & \text { maximal liquid mass absorbable by the granules } \\
& \eta_{\mathrm{G}} & \text { affinity factor of the granules }\left(\eta_{\mathrm{G}}>0\right) .
\end{array}
$$

(2.8) and (2.9) describe liquid masses which could be absorbed under optimal conditions. Usually, the restriction that the napkin's shape and volume has to be constant will avoid that this occurs.

For the masses $\mathrm{u}_{\mathrm{CA}}$ and $\mathrm{u}_{\mathrm{GA}}$, we can formally define corresponding concentrations

$$
c_{\mathrm{CA}}:=\eta_{\mathrm{C}} \cdot \frac{\mathrm{dm}_{\mathrm{C}}}{\mathrm{dV}} \quad \text { and } \quad c_{\mathrm{GA}}(\mathbf{x}):=\eta_{\mathrm{G}} \cdot \frac{\mathrm{dm}_{\mathrm{G}}}{\mathrm{dV}}(\mathbf{x})
$$

In general, $\mathrm{c}_{\mathrm{CA}}$ does not describe the concentration for completely saturated intermediate spaces. In a napkin the cellulose density $P_{C}$ is usually quite high, and so the cellulose has the affiniy to absorb more liquid than it is allowed by its restricted intermediate space.

In the sequel we will always consider such high cellulose densities. Then we know all the liquid in the intermediate spaces to be attached to the cellulose fibres. 
By defining the total mass as $\mathrm{M}:=\mathrm{m}_{\mathrm{C}}+\mathrm{m}_{\mathrm{G}}$ and introducing the granule-mass ratio

$$
\gamma(\mathbf{x}):=\frac{\mathrm{dm}_{\mathrm{G}}}{\mathrm{dM}}(\mathbf{x})
$$

one obtains

$$
\begin{aligned}
& c_{\mathrm{CA}}=\eta_{\mathrm{C}} \cdot \rho_{\mathrm{C}} \\
& \mathrm{c}_{\mathrm{GA}}(\mathbf{x})=\eta_{\mathrm{G}} \cdot \frac{\gamma(\mathbf{x})}{1-\gamma(\mathbf{x})} \cdot \rho_{\mathrm{C}} \quad(0 \leq \gamma(\mathbf{x})<1) .
\end{aligned}
$$

If liquid is put into a homogeneous granule-cellulose composite then both, granules and cellulose, exhibit the property to absorb the fluid. This absorbtion can be assumed to be reversible (cf. [1]). For $t \rightarrow \infty$ this leads to a dynamical equilibrium.

Now two questions arise.

i) How is the resultant equilibrium state characterized ?

ii) What is the temporal evolution towards this state ?

The first question can be answered by assuming the relation

$$
\frac{c_{\mathrm{GE}}(\mathbf{x})}{c_{\mathrm{CE}}}=\frac{\mathrm{c}_{\mathrm{GA}}(\mathbf{x})}{\mathrm{c}_{\mathrm{CA}}} .
$$

The index $\mathrm{E}$ describes the equilibrium state. The preceding ansatz implies that a constant concentration ratio is always reached, regardless of the available amount of liquid. For given $\eta_{\mathrm{C}}$ and $\eta_{\mathrm{G}}$, this ratio depends only on $\gamma(\mathbf{x})$.

To describe the temporal evolution, the following properties are taken to be valid.

- The rate of liquid transition from the cellulose to the granules is proportional to $c_{C}(\mathbf{x}, t)$ and $\left(c_{G A}(\mathbf{x})-c_{G}(\mathbf{x}, t)\right)$.

- The rate of liquid transition from the granules to the cellulose is proportional to $c_{\mathrm{G}}(\mathbf{x}, \mathrm{t})$ and $\left(\mathrm{c}_{\mathrm{CA}}-\mathrm{c}_{\mathrm{C}}(\mathbf{x}, \mathrm{t})\right)$.

This yields

$$
\frac{\partial \mathrm{c}_{\mathrm{G}}(\mathbf{x}, \mathrm{t})}{\partial \mathrm{t}}=\underset{\text { "forward reaction" }}{\mathrm{k} \cdot \mathrm{c}_{\mathrm{C}}(\mathbf{x}, \mathrm{t}) \cdot\left(\mathrm{c}_{\mathrm{GA}}(\mathbf{x})-\mathrm{c}_{\mathrm{G}}(\mathbf{x}, \mathrm{t})\right)-\mathrm{k}^{\prime} \cdot \mathrm{c}_{\mathrm{G}}(\mathbf{x}, \mathrm{t}) \cdot\left(\mathrm{c}_{\mathrm{CA}}-\mathrm{c}_{\mathrm{C}}(\mathbf{x}, \mathrm{t})\right)}
$$

with positive exchange constants $\mathrm{k}$ and $\mathrm{k}$ '. 
For the state of equilibrium, the left hand side of (2.13) is 0 . By plugging in (2.12), it is easiliy seen that $k$ and $k^{\prime}$ have to be equal.

Therefore one ends up with the final exchange equation

$$
\frac{\partial c_{G}(\mathbf{x}, t)}{\partial t}=k \cdot\left(c_{G A}(\mathbf{x}) \cdot c_{C}(\mathbf{x}, t)-c_{C A} \cdot c_{G}(\mathbf{x}, t)\right)
$$

It should be noticed that the exchange process uses concentrations which are related to the total volume. This is in contrast to the diffusion process which has to be related to the intermediate space volume.

\subsection{The Mathematical Model}

Changes in the fluid concentrations in the cellulose are either caused by diffusion in the intermediate spaces or by liquid exchange between cellulose and granules. Changes in the fluid concentrations in the granules are only due to the exchange being described by equation (2.14). Hence we obtain the "napkin equations"

$$
\begin{array}{ll}
\frac{\partial c_{C}(\mathbf{x}, t)}{\partial t}= & \operatorname{div}\left(\frac{d V_{I}}{d V}(\mathbf{x}, t) \cdot d\left(\tilde{c}_{C}(\mathbf{x}, t)\right) \cdot \operatorname{grad}\left(\tilde{c}_{C}(\mathbf{x}, t)\right)\right)-\frac{\partial c_{G}(\mathbf{x}, t)}{\partial t} \\
\frac{\partial c_{G}(\mathbf{x}, t)}{\partial t}= & k \cdot\left(c_{G A}(\mathbf{x}) \cdot c_{C}(\mathbf{x}, t)-c_{C A} \cdot c_{G}(\mathbf{x}, t)\right) \\
\text { with } \quad & \frac{d V_{I}}{d V}(\mathbf{x}, t)=1-\frac{\rho_{C}}{\rho_{F}}-\frac{c_{G}(\mathbf{x}, t)}{\rho_{U}} \\
& \tilde{c}_{C}(\mathbf{x}, t)=c_{C}(\mathbf{x}, t) / \frac{d V_{I}}{d V}(\mathbf{x}, t) \\
& d\left(\tilde{c}_{C}\right)=d_{0} \cdot \exp \left(\beta \cdot \tilde{c}_{C}\right) .
\end{array}
$$

The preceding equations consist of a nonlinear diffusion equation strongly coupled with an ordinary differential equation in $\mathrm{c}_{\mathrm{G}}$. The nonlinearity is caused by the diffusivity (2.7), while the strong coupling is due to the intermediate space related description of the diffusion (cf. (2.3), (2.5)).

These equations have to be completed with suitable initial and boundary conditions. Let us start with the boundary conditions by defining a convenient geometry which models the real life process sufficiently well (Fig. 3). 


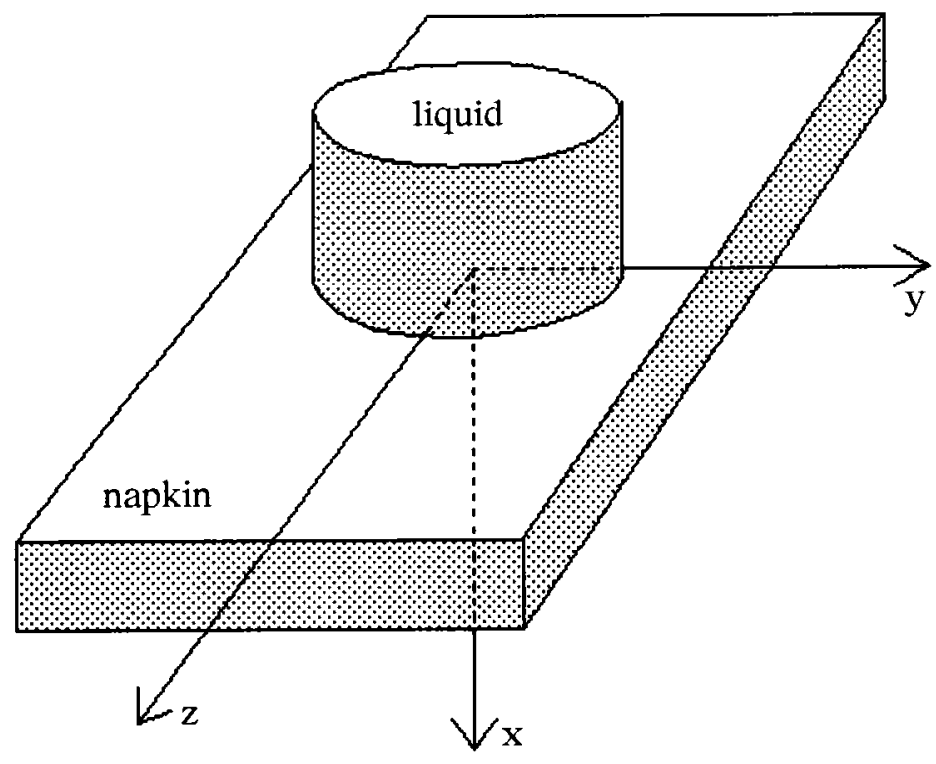

Fig. 3. Model geometry

The model napkin we are concerned with is a block $\bar{W}$ with

$$
\mathrm{W}:=\left(0, \mathrm{x}_{\max }\right) \times\left(-\mathrm{y}_{\max }, \mathrm{y}_{\max }\right) \times\left(-\mathrm{z}_{\max }, \mathrm{z}_{\max }\right)
$$

The liquid to be absorbed is represented by the a cylinder with fixed radius $R$. Its volume shall contain a liquid mass $Q$.

The origin of the coordinate system is given by the centre of the upper napkin surface and the centre of the cylinder bottom is placed in this location. According to figure 3 the problem is symmetrical with respect to the planes $y=0$ and $z=0$, a fact that will be taken advantage of for saving calculation time in the numerical approximation.

The boundary $\partial \mathrm{W}$ can be split into two parts.

$$
\begin{aligned}
& \partial W_{1}:=\text { upper napkin surface below the cylinder } \\
& \partial W_{2}:=\partial W \backslash \partial W_{1} .
\end{aligned}
$$

Denoting by $\mathrm{T}$ the time for complete liquid absorbtion and by $\mathbf{n}$ the outer normal vector we require as boundary conditions

$$
\begin{array}{ll}
\text { for } 0<\mathrm{t} s \mathrm{~T}: & \left.\tilde{\mathrm{c}}_{\mathrm{C}}\right|_{\partial \mathrm{W}_{1}}=\rho_{\mathrm{U}} \\
\text { for } \mathrm{t}>\mathrm{T}: & \left.\frac{\partial \tilde{\mathrm{c}}_{\mathrm{C}}}{\partial \mathbf{n}}\right|_{\partial \mathrm{W}_{2}}=0 \\
& \left.\frac{\partial \tilde{\mathrm{c}}_{\mathrm{C}}}{\partial \mathbf{n}}\right|_{\partial \mathrm{W}}=0 .
\end{array}
$$


At corners and edges $\mathbf{n}$ is supposed to be orthogonal to every adjoining surface. As initial conditions we take

$$
\begin{array}{ll}
\mathfrak{c}_{\mathrm{C}}(\mathbf{x}, 0)=\varphi_{\mathrm{C}}(\mathbf{x}) & \forall \mathbf{x} \in \mathrm{W} \\
\mathrm{c}_{\mathrm{G}}(\mathbf{x}, 0)=\varphi_{\mathrm{G}}(\mathbf{x}) & \forall \mathbf{x} \in \mathrm{W} .
\end{array}
$$

For a new napkin, $\varphi_{C}$ and $\varphi_{G}$ will be set to zero. If one considers rewetting into a used napkin, one has to admit other functions as well.

We conclude this chapter by summarizing all parameters which are used in our model.

$\begin{array}{ll}\text { densities } & \rho_{\mathrm{U}}, \rho_{\mathrm{C}}, \rho_{\mathrm{F}} \\ \text { parameters for the diffusivity } & \mathrm{d}_{0}, \beta \\ \text { exchange constant } & \mathrm{k} \\ \text { affinity factors } & \eta_{\mathrm{C}}, \eta_{\mathrm{G}} \\ \text { size of the napkin } & \mathrm{x}_{\text {max }}, \mathrm{y}_{\text {max }}, \mathrm{z}_{\text {max }} \\ \text { radius of the liquid cylinder } & \mathrm{R} \\ \text { liquid mass } & \mathrm{Q} \\ \text { local granule-mass ratio } & \gamma(\mathbf{x})\end{array}$

Some of these parameters are well-known biological values (e.g. $Q, \rho_{U}$ ), others like $d_{0}, \beta$ can be easily determined by suitable experiments [6].

In chapter 4 the granule-mass ratio $\gamma(\mathbf{x})$ is used as a design parameter to develop improved napkins. 


\section{NUMERICAL APPROXIMATION}

Since the initial boundary value problem (2.15)-(2.21) is highly complicated, we cannot expect to find an analytical solution. We assume that for $\mathrm{t}>0$ a global unique solution in the classical sense exists and we focus on the study of numerical approximations.

\subsection{Time Splitting}

For a numerical treatment of the napkin equations it is advantegeous to split the coupled diffusion and exchange phenomenon into a suitable sequence of pure diffusion and pure exchange processes by the method of fractional steps $[7,10]$.

We assemble $c_{C}$ and $c_{G}$ in a vector field

$$
\mathbf{c}(\mathbf{x}, \mathrm{t}):=\left(\begin{array}{l}
c_{\mathrm{C}}(\mathbf{x}, \mathrm{t}) \\
\mathrm{c}_{\mathrm{G}}(\mathbf{x}, \mathrm{t})
\end{array}\right)
$$

and define a diffusion operator $\mathbf{D}$ and an exchange operator $\mathbf{E}$ by

$$
\begin{aligned}
& D\left(\begin{array}{l}
c_{C} \\
c_{G}
\end{array}\right):=\left(\operatorname{div}\left(\left(1-\alpha-\frac{c_{G}}{\rho_{U}}\right) \cdot d\left(\frac{c_{C}}{1-\alpha-c_{G} / \rho_{U}}\right) \cdot \operatorname{grad}\left(\frac{c_{C}}{1-\alpha-c_{G} / \rho_{U}}\right)\right)\right. \\
& 0 \\
& E\left(\begin{array}{l}
c_{C} \\
c_{G}
\end{array}\right):=k \cdot\left(c_{G A} c_{C}-c_{C A} c_{G}\right) \cdot\left(\begin{array}{c}
-1 \\
1
\end{array}\right) \\
& \text { with } \alpha:=\frac{\rho_{C}}{\rho_{F}} .
\end{aligned}
$$

Then the napkin equations $(2.15),(2.16)$ can be written as

$$
\frac{\partial \mathbf{c}}{\partial t}=(\mathbf{D}+\mathbf{E}) \mathbf{c}
$$

For discretizing in time we introduce

$$
\begin{aligned}
& t_{0}:=0 \\
& t_{n+1}:=t_{n}+\tau_{n+1} \quad \forall n \in \mathbb{N}_{0} .
\end{aligned}
$$

The time step size $\tau_{n+1}$ may vary from step to step according to the automatic step size control to be described later. In the sequel we will suppress the index and denote by $\tau$ the instantaneous time step size. 
The method of fractional steps for a symmetrical operator splitting consists of replacing

$$
\frac{\partial \mathbf{c}}{\partial t}=(\mathbf{D}+\mathbf{E}) \mathbf{c} \quad \text { for } t \in\left[t_{n}, t_{n+1}\right]
$$

by

$$
\begin{array}{ll}
\frac{1}{4} \frac{\partial c}{\partial t}=\frac{1}{2} E \mathbf{c} & \text { for } t \in\left[t_{n}, t_{n+1 / 4}\right] \\
\frac{1}{2} \frac{\partial c}{\partial t}=D c & \text { for } t \in\left[t_{n+1 / 4}, t_{n+3 / 4}\right] \\
\frac{1}{4} \frac{\partial c}{\partial t}=\frac{1}{2} E c & \text { for } t \in\left[t_{n+3 / 4}, t_{n+1}\right]
\end{array}
$$

For sufficiently smooth functions it can be shown by Taylor expansions that this symmetrical time splitting is consistent of order $\mathrm{O}\left(\tau^{2}\right)$.

The quadratic consistency order is not altered if the intermediate steps are replaced by approximations of order $\mathrm{O}\left(\tau^{2}\right)$. Consequently, we have to employ solvers for the pure exchange and for the pure diffusion equation, which are consistent of (at least) quadratic order. This is done in the next two scctions.

\subsection{Analytical Solution of the Exchange Equation}

For the first and third intermediate step of the preceding time splitting it is necessary to solve an initial value problem of the type

$$
\begin{aligned}
& \frac{\partial \mathbf{c}}{\partial \mathrm{t}}(\mathbf{x}, \mathrm{t})=2 \mathrm{E}(\mathbf{c}(\mathbf{x}, \mathrm{t})) \\
& \mathbf{c}\left(\mathbf{x}, \mathrm{t}_{0}\right)=\left(\begin{array}{l}
\Psi_{\mathrm{C}}(\mathbf{x}) \\
\Psi_{\mathrm{G}}(\mathbf{x})
\end{array}\right) . \quad\left(\Psi_{\mathrm{C}}, \Psi_{\mathrm{G}}: \mathbb{R}^{3} \longrightarrow \mathbb{R}\right)
\end{aligned}
$$

It can be easily seen by definition (3.2) of the exchange operator $\mathbf{E}$ that for each location $\mathbf{x}$ the total liquid amount is constant in time. Therefore one has

$$
\mathrm{c}_{\mathrm{G}}(\mathbf{x}, \mathrm{t})+\mathrm{c}_{\mathrm{C}}(\mathbf{x}, \mathrm{t})=\Psi_{\mathrm{G}}(\mathbf{x})+\Psi_{\mathrm{C}}(\mathbf{x})=: \lambda(\mathbf{x}) \quad \forall \mathrm{t} \geq \mathrm{t}_{0}
$$


Using this definition the second component of (3.7) becomes

$$
\frac{\partial \mathrm{c}_{\mathrm{G}}}{\partial \mathrm{t}}(\mathbf{x}, \mathrm{t})=2 \mathrm{k} \cdot\left(\lambda(\mathbf{x}) \cdot \mathrm{c}_{\mathrm{GA}}(\mathbf{x})-\mathrm{c}_{\mathrm{G}}(\mathbf{x}, \mathrm{t}) \cdot\left(\mathrm{c}_{\mathrm{CA}}+\mathrm{c}_{\mathrm{GA}}(\mathbf{x})\right)\right)
$$

with initial condition

$$
c_{G}\left(\mathbf{x}, t_{0}\right)=\Psi_{G}(\mathbf{x})
$$

For fixed $\mathbf{x}$ equation (3.10) is an ODE in $c_{G}$. By standard techniques one shows that the initial value problem (3.10), (3.11) has the unique global solution

$$
\begin{array}{ll}
\mathrm{c}_{\mathrm{G}}(\mathbf{x}, \mathrm{t})=\alpha_{1}(\mathbf{x})+\left(\Psi_{\mathrm{G}}(\mathbf{x})-\alpha_{1}(\mathbf{x})\right) \cdot \exp \left(-\alpha_{2}(\mathbf{x}) \cdot\left(\mathrm{t}-\mathrm{t}_{0}\right)\right) \\
\text { with } \quad \alpha_{1}(\mathbf{x}):=\frac{\lambda(\mathbf{x}) \cdot \mathrm{c}_{\mathrm{GA}}(\mathbf{x})}{\mathrm{c}_{\mathrm{CA}}+\mathrm{c}_{\mathrm{GA}}(\mathbf{x})} \\
\text { and } & \alpha_{2}(\mathbf{x}):=2 \mathrm{k} \cdot\left(\mathrm{c}_{\mathrm{CA}}+\mathrm{c}_{\mathrm{GA}}(\mathbf{x})\right) .
\end{array}
$$

The concentration $c_{C}(\mathbf{x}, t)$ can be calculated from $c_{G}(x, t)$ using (3.9). Hence the pure exchange step is solvable analytically.

\subsection{Numerical Approximation of the Diffusion Equation}

From definition (3.1) of the diffusion operator D we know that for a pure diffusion step the liquid concentration $c_{G}$ is constant in time. Thus one can write

$$
\frac{\mathrm{dV}_{\mathrm{I}}}{\mathrm{dV}}(\mathbf{x}, \mathrm{t})=1-\frac{\rho_{\mathrm{C}}}{\rho_{\mathrm{F}}}-\frac{\mathrm{c}_{\mathrm{G}}(\mathbf{x}, \mathrm{t})}{\rho_{\mathrm{U}}}=: \boldsymbol{\vartheta}(\mathbf{x})
$$

Using the chain rule and the definition above the pure diffusion equation (2.4) becomes

$$
\frac{\partial \widetilde{\mathbf{c}}_{\mathrm{C}}(\mathbf{x}, \mathrm{t})}{\partial \mathrm{t}}=\frac{1}{\vartheta(\mathbf{x})} \cdot \operatorname{div}\left(\vartheta(\mathbf{x}) \cdot \mathrm{d}\left(\tilde{\mathbf{c}}_{\mathrm{C}}(\mathbf{x}, \mathrm{t})\right) \cdot \operatorname{grad}\left(\tilde{\mathbf{c}}_{\mathrm{C}}(\mathbf{x}, \mathrm{t})\right)\right)
$$

It should be noted that (3.14) contains only one type of concentration, namely $\widetilde{c}_{\mathrm{C}}$. 
However, this nonlinear equation is still too complicatad for an analytical solution, hence it has to be treated numerically.

Various finite difference schemes, explicit or implicit, with two or three time levels [8], were implemented and compared. In the following we focus on the description of an ADI-predictor-corrector method which turned out to be the best of the ones that were experienced.

By introducing the step sizes

$$
\begin{array}{lll}
h_{1}:=x_{\max } / N_{1} & \text { step size in } x \text { direction } \\
h_{2}:=y_{\max } / N_{2} & \text { step size in } y \text { direction } \\
h_{3}:=z_{\max } / N_{3} & \text { step size in } z \text { direction }
\end{array}
$$

and the grid points

$$
\mathbf{x}_{\mathrm{ijk}}:=\left(\begin{array}{c}
\left(\mathrm{i}-\frac{1}{2}\right) \mathrm{h}_{1} \\
\left(\mathrm{j}-\frac{1}{2}\right) \mathrm{h}_{2} \\
\left(\mathrm{k}-\frac{1}{2}\right) \mathrm{h}_{3}
\end{array}\right) \quad\left(1 \leq \mathrm{i} \leq \mathrm{N}_{1}, \quad 1 \leq \mathrm{j} \leq \mathrm{N}_{2}, \quad 1 \leq \mathrm{k} \leq \mathrm{N}_{3}\right)
$$

a grid $\Gamma$ is defined by

$$
\Gamma:=\left\{\mathbf{x}_{i j k} \mid 1 \leq \mathrm{i} \leq \mathrm{N}_{1}, \quad 1 \leq \mathrm{j} \leq \mathrm{N}_{2}, \quad 1 \leq \mathrm{k} \leq \mathrm{N}_{3}\right\}
$$

A finite difference solver with second order consistency can be obtained by a scheme of Crank-Nicolson type [2], i.e

$$
\frac{\mathbf{u}^{n+1}-\mathbf{u}^{n}}{\tau}=\sum_{i=1}^{3} L_{i}\left(\boldsymbol{\mu}, \frac{\mathbf{u}^{\mathrm{n}+1}+\mathbf{u}^{\mathrm{n}}}{2}\right) \frac{\mathbf{u}^{\mathrm{n}+1}+\mathbf{u}^{\mathrm{n}}}{2}+\mathbf{f}^{\mathrm{n}}
$$

with

$$
\begin{array}{ll}
\mathbf{u}^{\mathrm{n}} & \text { approximation of } \tilde{c}_{\mathrm{C}}\left(\mathbf{x}, \mathrm{t}_{\mathrm{n}}\right) \text { in } \Gamma \text { (contains } \mathrm{N}_{1} \cdot \mathrm{N}_{2} \cdot \mathrm{N}_{3} \text { components) } \\
\boldsymbol{\mu} & \text { approximation of } \vartheta(\mathbf{x}) \text { at the grid points } \\
\mathbf{f}^{\mathrm{n}} & \text { term arising from the Dirichlet boundary condition }(2.17) \\
\mathrm{L}_{\mathrm{i}} & \text { discrete approximation of } \\
& \frac{1}{\vartheta(\mathbf{x})} \cdot \frac{\partial}{\partial x}\left(\vartheta(\mathbf{x}) \cdot \mathrm{d}\left(\tilde{\mathrm{c}}_{\mathrm{c}}(\mathbf{x}, t)\right) \cdot \frac{\partial}{\partial x}\right) \quad \text { for } \mathrm{i}=1
\end{array}
$$




$$
\begin{array}{ll}
\frac{1}{\vartheta(\mathbf{x})} \cdot \frac{\partial}{\partial y}\left(\vartheta(\mathbf{x}) \cdot \mathrm{d}\left(\tilde{\mathrm{c}}_{\mathrm{c}}(\mathbf{x}, \mathrm{t})\right) \cdot \frac{\partial}{\partial y}\right) & \text { for } \mathrm{i}=2 \\
\frac{1}{\vartheta(\mathbf{x})} \cdot \frac{\partial}{\partial z}\left(\vartheta(\mathbf{x}) \cdot \mathrm{d}\left(\tilde{\mathrm{c}}_{\mathrm{c}}(\mathbf{x}, \mathrm{t})\right) \cdot \frac{\partial}{\partial z}\right) & \text { for } \mathrm{i}=3
\end{array}
$$

For this algorithm it is necessary to solve a nonlinear system of $\mathrm{N}_{1} \cdot \mathrm{N}_{2} \cdot \mathrm{N}_{3}$ equations in each step. To avoid the inversion of nonlinear expressions, (3.15) can be replaced by the predictor-corrector version [5]

$$
\begin{aligned}
& \frac{\mathbf{u}^{n+1 / 2}-\mathbf{u}^{n}}{\tau / 2}=\sum_{i=1}^{3} L_{i}\left(\boldsymbol{\mu}, \mathbf{u}^{n}\right) \frac{\mathbf{u}^{n+1 / 2}+\mathbf{u}^{n}}{2}+\mathbf{f}^{n} \\
& \frac{\mathbf{u}^{n+1}-\mathbf{u}^{n}}{\tau}=\sum_{i=1}^{3} L_{i}\left(\boldsymbol{\mu}, \mathbf{u}^{n+1 / 2}\right) \frac{\mathbf{u}^{n+1}+\mathbf{u}^{n}}{2}+\mathbf{f}^{n} .
\end{aligned}
$$

The predictor step (3.16) is used to calculate $\mathbf{u}^{\mathrm{n}+1 / 2}$, an approximation for the argument $\left(\mathbf{u}^{n+1}+\mathbf{u}^{n}\right) / 2$ of the nonlinear operators $L_{1}, L_{2}$ and $L_{3}$. Therefore the predictorcorrector scheme (3.16), (3.17) leads to two linear systems instead of one nonlinear system.

However, if we discretize by the standard 7-point formula and use line ordering, the linear systems contain heptadiagonal matrices with large bandwidth. Since our problem is three dimensional, even coarse discretizations lead to a lot of grid points. Hence it is necessary to find a very fast and storage saving solver. One possibility to avoid these problems is to replace (3.16), (3.17) by their ADI approximations in the sense of Douglas and Gunn [4] yielding

$$
\text { predictor step: }
$$

$$
\frac{\mathbf{u}^{n+1 / 6}-\mathbf{u}^{n}}{\tau / 2}=\frac{1}{2} L_{1}\left(\boldsymbol{\mu}, \mathbf{u}^{n}\right)\left(\mathbf{u}^{n+1 / 6}-\mathbf{u}^{n}\right)+\sum_{i=1}^{3} L_{i}\left(\boldsymbol{\mu}, \mathbf{u}^{n}\right) \mathbf{u}^{n}+\mathbf{f}^{n}
$$

$$
\frac{\mathbf{u}^{\mathrm{n}+2 / 6}-\mathbf{u}^{\mathrm{n}+1 / 6}}{\tau / 2}=\frac{1}{2} \mathrm{~L}_{2}\left(\boldsymbol{\mu}, \mathbf{u}^{\mathrm{n}}\right)\left(\mathbf{u}^{\mathrm{n}+2 / 6}-\mathbf{u}^{\mathrm{n}}\right)
$$

$$
\frac{\mathbf{u}^{n+1 / 2}-\mathbf{u}^{\mathrm{n}+2 / 6}}{\tau / 2}=\frac{1}{2} \mathrm{~L}_{3}\left(\boldsymbol{\mu}, \mathbf{u}^{\mathrm{n}}\right)\left(\mathbf{u}^{\mathrm{n}+1 / 2}-\mathbf{u}^{\mathrm{n}}\right)
$$


corrector step:

$$
\begin{aligned}
& \frac{\mathbf{u}^{n+1 / 3}-\mathbf{u}^{n}}{\tau}=\frac{1}{2} L_{1}\left(\boldsymbol{\mu}, \mathbf{u}^{n+1 / 2}\right)\left(\mathbf{u}^{n+1 / 3}-\mathbf{u}^{n}\right)+\sum_{i=1}^{3} L_{i}\left(\boldsymbol{\mu}, \mathbf{u}^{n+1 / 2}\right) \mathbf{u}^{n}+\mathbf{f}^{n} \\
& \frac{\mathbf{u}^{n+2 / 3}-\mathbf{u}^{n+1 / 3}}{\tau}=\frac{1}{2} L_{2}\left(\boldsymbol{\mu}, \mathbf{u}^{n+1 / 2}\right)\left(\mathbf{u}^{n+2 / 3}-\mathbf{u}^{n}\right) \\
& \frac{\mathbf{u}^{n+1}-\mathbf{u}^{n+2 / 3}}{\tau}=\frac{1}{2} L_{3}\left(\boldsymbol{\mu}, \mathbf{u}^{n+1 / 2}\right)\left(\mathbf{u}^{n+1}-\mathbf{u}^{n}\right) .
\end{aligned}
$$

What are the advantages of this ADI-predictor-corrector scheme?

In each of the six intermediate steps the problem is implicit only in one space dimension leading to diagonally dominant tridiagonal systems. Since these systems can be solved with linear effort by a modified Gaussian algorithm [9], the total scheme (3.18)-(3.23) is solvable with a computational and storage effort, which depends linearly on the number of grid points.

Furthermore, by elimination of the intermediate steps and by the use of Taylor's expansions it can be shown that (3.18)-(3.23) is consistent of second order in space and time. Therefore the ADI-predictor-corrector method can be interpreted as an efficient second order approximation of the Crank-Nicolson scheme (3.15).

\subsection{Time Step Size Control}

Numerical experiments indicate that for a each granule distribution there exists a $\mathbf{r}_{\max }>0$ such that for

$$
\tau \cdot \max _{n}\left(d\left(\left\|\mathbf{u}^{\mathrm{n}}\right\|_{\infty}\right)\right) \cdot\left(\frac{1}{\mathrm{~h}_{1}^{2}}+\frac{1}{\mathrm{~h}_{2}^{2}}+\frac{1}{\mathrm{~h}_{3}^{2}}\right)>\mathrm{r}_{\max }
$$

instabilities arise. This inequality can be used to construct an automatic time step size control.

For $\mathrm{t} \leq \mathrm{T}$ there is still liquid inside the cylinder and by the Dirichlet boundary condition (2.17) the maximal saturation $\left\|\mathbf{u}^{\mathrm{n}}\right\|_{\infty}$ can be replaced by $\rho_{U}$. For $t>T$ $\left\|\mathbf{u}^{\mathrm{n}}\right\|_{\infty}$ and $\mathrm{d}\left(\left\|\mathbf{u}^{\mathrm{n}}\right\|_{\infty}\right)$ decrease, hence it is possible to enlarge the time step size $\tau$. The step size control algorithm reads as follows. 


$$
\begin{aligned}
& \text { choose } r \in\left(0, r_{\max }\right] \\
& \text { for } t_{n} \leq T: \quad \tau:=\frac{r}{d\left(\rho_{U}\right) \cdot\left(\frac{1}{h_{1}^{2}}+\frac{1}{h_{2}^{2}}+\frac{1}{h_{3}^{2}}\right)} \\
& \text { for } t_{n}>T: \quad \tau:=\frac{r}{d\left(\left\|u^{n}\right\|_{\infty}\right) \cdot\left(\frac{1}{h_{1}^{2}}+\frac{1}{h_{2}^{2}}+\frac{1}{h_{3}^{2}}\right)}
\end{aligned}
$$

In our special case, this step size algorithm works very well. By (2.7), the diffusivity increases exponentially with the intermediate space saturation, so even small decreases of $\left\|\mathbf{u}^{\mathrm{n}}\right\|_{\infty}$ yield drastically enlarged time step sizes. For the real-life examples in chapter 4 and a simulation time for the first 6 hours the number of required iterations was reduced by a factor between 160 and 200 .

\subsection{The Computer Programme}

In order to permit a comfortable simulation, a menue driven computer programme was developed with the following properties.

a) At the beginning the programme describes the mathematical model, the numerical schemes and the way how to use the computer simulation.

b) The physical and biological parameters are read from a file.

c) Typical programme parameters like initial state of the napkin, numerical method, step size control parameter, output mode or the choice of the granule distribution can either be read from a file or typed in by hand.

d) After the programme is started, it can be interrupted by pressing any key. A menue appears which allows continuation with modified parameters, the storage of results or restart.

e) Different output variables are possible and the output data can be stored by file, written on the screen or visualized by colour graphics. Arbitrary sections perpendicular to all three coordinate directions are possible. The graphical representation can be refined by linear interpolation.

f) In order to find the best numerical scheme different test modi are available: Comparison with the results obtained with half time step size or comparison between different solvers. 
The source code was written in PASCAL and it exhibits a length of approximately 5200 lines. In order to ensure good portability properties the ISO standard was used everywhere excluding only the file handling, the keypress routine and the graphics part.

The code was implemented on a Hewlett Packard workstation HP 9000-835 SRX (RISC CPU, 14 MIPS, 3 MFLOPS) and for graphical visualization Starbase routines were included. For typical calculations over a time interval of 3 hours (see chapter 4) only a few minutes are necessary. 


\section{APPLICATION TO REAL-LIFE PROBLEMS}

\subsection{Investigation of Current Napkins}

For the applications of the previously described model we choose the following values for the biological and physical parameters that appear to be fairly realistic:

$\begin{array}{llll}\text { densities } & \rho_{\mathrm{F}} & :=1 \mathrm{~g} / \mathrm{cm}^{3} \\ & \rho_{\mathrm{C}} & :=0.1 \mathrm{~g} / \mathrm{cm}^{3} \\ & \rho_{\mathrm{U}} & :=1 \mathrm{~g} / \mathrm{cm}^{3} \\ \text { parameters for the diffusivity } & \mathrm{d}_{0}:=10^{-4} \mathrm{~cm}^{2} / \mathrm{s} \\ & \beta & :=11 \mathrm{~cm}^{3} / \mathrm{g} \\ \text { affinity factors } & \eta_{\mathrm{G}}:=65 \\ & \eta_{\mathrm{C}}:=10 \\ \text { exchange constant } & \mathrm{k} & :=3 \cdot 10^{-3} \mathrm{~cm}^{3} /(\mathrm{g} \cdot \mathrm{s}) \\ \text { size of the napkin } & \mathrm{x}_{\max }:=1 \mathrm{~cm} \\ & \mathrm{y}_{\max }:=5 \mathrm{~cm} \\ & \mathrm{z}_{\max }:=15 \mathrm{~cm} \\ \text { liquid cylinder radius } & \mathrm{R} & :=3 \mathrm{~cm} \\ \text { liquid mass } & \mathrm{Q} & :=75 \mathrm{~g} .\end{array}$

The numerical parameters have been $r:=2$ for the time step size control and

$$
\begin{aligned}
& N_{1}:=4 \\
& N_{2}:=5 \\
& N_{3}:=10
\end{aligned}
$$

for the number of grid points in $\mathrm{x}, \mathrm{y}$ and $\mathrm{z}$ direction.

Let us first investigate gluing effects in Ultra napkins.

Figure 4 describes a comparison between a granule-free napkin and an Ultra napkin with respect to the total saturation

$$
s(\mathbf{x}, \mathrm{t}):=\frac{c_{\mathrm{C}}(\mathbf{x}, \mathrm{t})+\mathrm{c}_{\mathrm{G}}(\mathbf{x}, \mathrm{t})}{\left(1-\rho_{\mathrm{C}} / \rho_{\mathrm{F}}\right) \cdot \rho_{\mathrm{U}}}
$$

A homogeneous granule distribution with $\gamma:=0.1$ was chosen and the saturation after three hours is depicted for the points $\left(\mathbf{x}_{11 \mathrm{k}}\right)_{\mathrm{k}}$. 


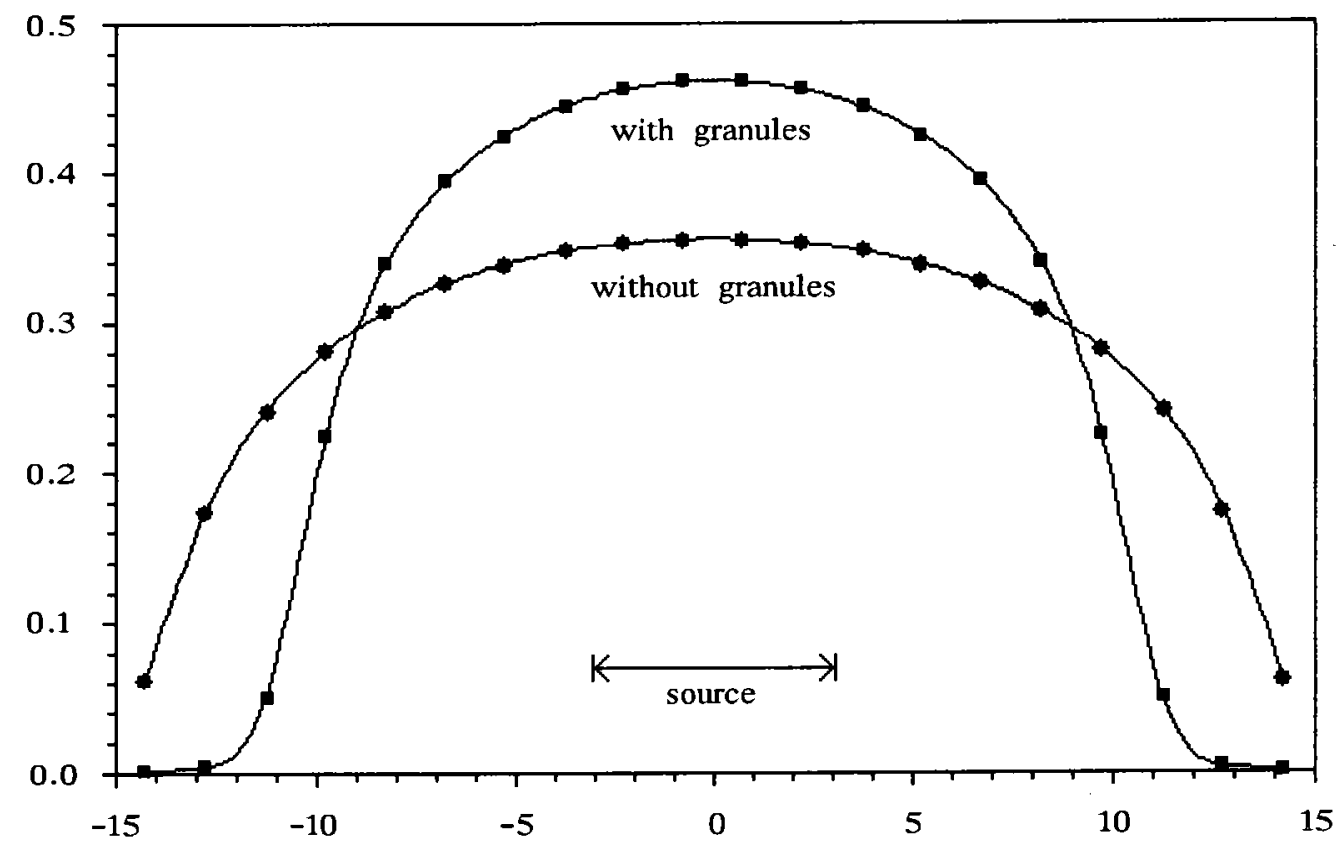

Fig. 4. Saturation profile in $z[\mathrm{~cm}]$ direction

The Ultra napkin differs from the granule-free one by smaller extension of the humid region, a higher saturation in these locations and sharper frontiers between dry and humid area. This is due to the expanded granules which have occupied much of the intermediate space. Therefore on one hand transport in the cellulose is hindered, on the other hand much of the liquid is fixed in the granules (recall that the granules exhibit no transport properties).

In a next step we investigate the reversibility of the liquid exchange between cellulose and granules. Reversibility implies the possibility for a liquid transition backwards from granules to cellulose. Is this desorbtion an important effect?

Figure 5 describes the time evolution of the liquid concentration in the granules at a point near the origin (which is the location with the most significant desorbtion). At the beginning the concentration increases due to the large liquid offer from the source. Afterwards, liquid in the cellulose is transported away from the origin, hence causing a desorbtion in the granules at the location we consider. From figure 5 we recognize that this desorbtion is quite slow and not very important. This indicates the usefulness of the granules: they help to keep the baby dry by absorbing large amounts of liquid with only small transition from granules to cellulose. 


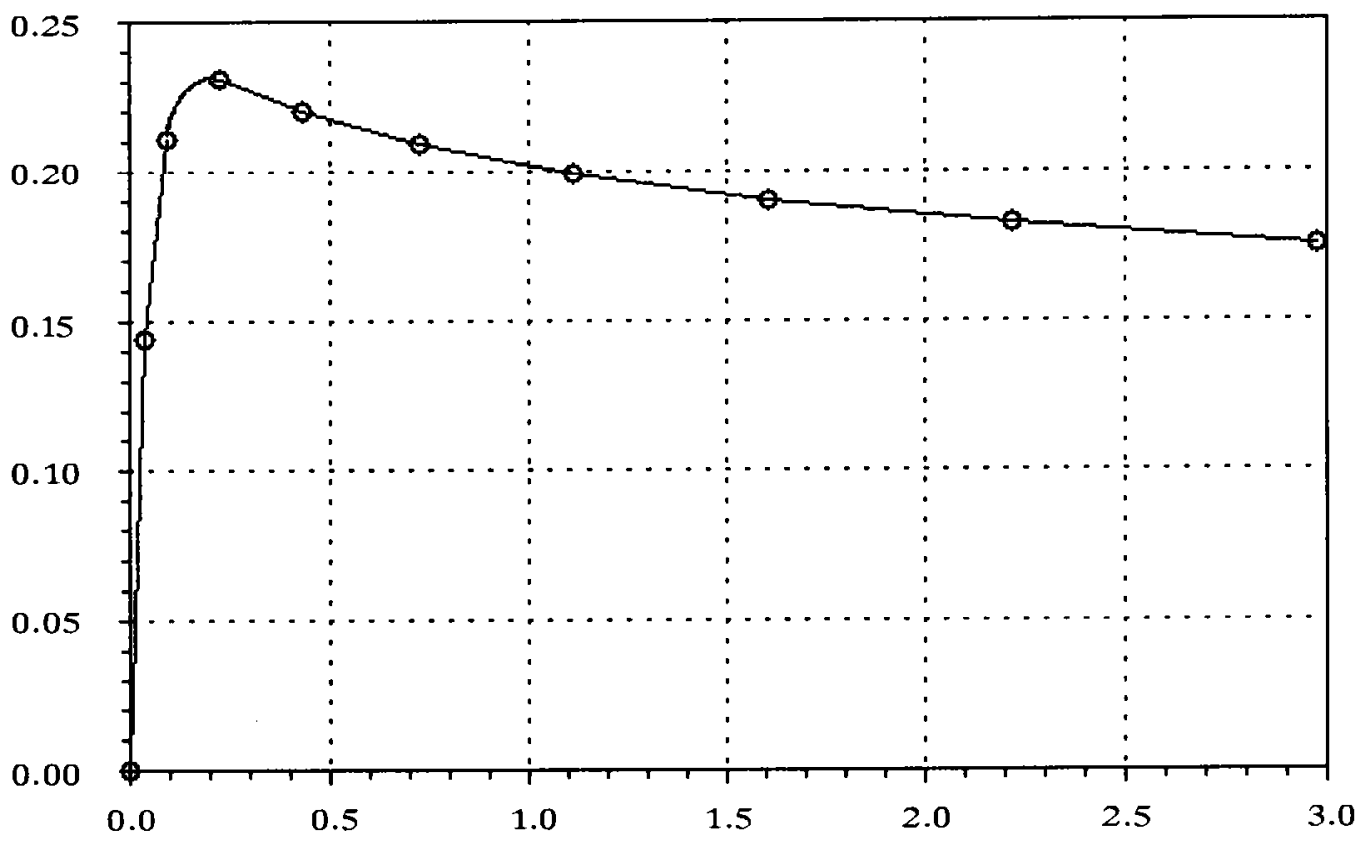

Fig. 5. Concentration $c_{G}\left[g / \mathrm{cm}^{3}\right]$ at $x_{111}$ vs. time $t[h]$

\subsection{Suggestions for Improved Napkins}

Before we can use our model for improving napkins it is necessary to define qualities of a good napkin. Two properties are essential:

a) The time $\mathrm{T}$ for complete liquid absorbtion should be as small as possible.

b) The napkin should remain dry at the surface which is in contact with the baby.

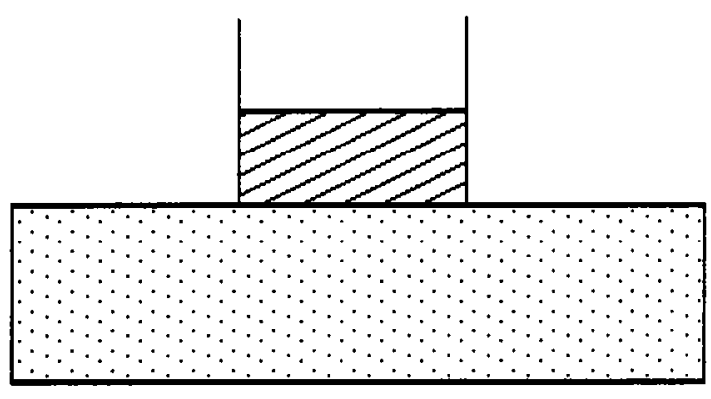

Fig. 6. Homogeneous granule distribution

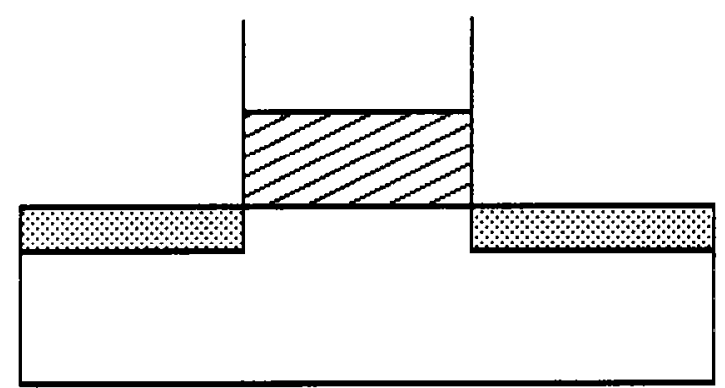

Fig. 7. Inhomogeneous granule distribution

Figure 6 shows a conventional Ultra napkin consisting of a homogeneous mixture of granules and cellulose with a liquid cylinder at the top. A proposal for a better napkin is described in figure 7 . While using the same amount of granules, it differs by an 
inhomogeneous granule distribution. In order to achieve a short time for liquid absorbtion (requirement (a)), no granules are placed below the liquid cylinder. Since it is aimed to keep the baby dry (requirement (b)), the granules are concentrated inside a layer of thickness $x_{\max } / 4$ at the top of the napkin excluding only the granule-free zone below the cylinder.

The following calculations quantify the improvements that are achieved in the present model setting.

\section{a) Absorbtion Time}

Table 1 compares different kinds of napkins with respect to the time for complete liquid absorbtion and with respect to gluing effects. Concerning these criteria a napkin without any granules is optimal: no gluing effects caused by increasing granule volume appear and hence the absorbtion time $T$ is minimal. However, for the first wetting Ultra napkins with homogeneous or inhomogeneous granule distribution are hardly worse. Their absorbtion time delay compared with the granule-free napkin is negligible. The reason is the fact that liquid absorbtion by the granules is much slower than absorbtion by cellulose. Usually it takes several minutes until granules have absorbed a larger amount of liquid (cf. figure 5), while absorbtion by the cellulose is a matter of seconds. Therefore gluing effects are not important for the first wetting.

Table 1. Absorbtion properties for the first wetting

\begin{tabular}{|c|c|c|c|}
\hline & $\begin{array}{c}\text { granule-free } \\
\text { napkin }\end{array}$ & $\begin{array}{c}\text { homogeneous } \\
\text { Ultra napkin }\end{array}$ & $\begin{array}{c}\text { inhomogeneous } \\
\text { Ultra napkin }\end{array}$ \\
\hline absorbtion time & $11.10 \mathrm{~s}$ & $11.18 \mathrm{~s}$ & $11.15 \mathrm{~s}$ \\
\hline $\begin{array}{c}\text { delay caused } \\
\text { by gluing effects }\end{array}$ & ---- & $0.08 \mathrm{~s}$ & $0.05 \mathrm{~s}$ \\
\hline
\end{tabular}

For the second wetting after 3 hours the situation is different (table 2). Meanwhile the granules in the Ultra napkins became a gel and hence they enlarge the absorbtion time significantly. However, the infuence of gluing can be reduced by $60 \%$ when the preceding inhomogeneous granule distribution is applied. 
Table 2. Absorbtion properties for the second wetting

\begin{tabular}{|c|c|c|c|}
\hline & $\begin{array}{c}\text { granule-free } \\
\text { napkin }\end{array}$ & $\begin{array}{c}\text { homogeneous } \\
\text { Ultra napkin }\end{array}$ & $\begin{array}{c}\text { inhomogeneous } \\
\text { Ultra napkin }\end{array}$ \\
\hline absorbtion time & $19.20 \mathrm{~s}$ & $29.08 \mathrm{~s}$ & $23.15 \mathrm{~s}$ \\
\hline $\begin{array}{c}\text { delay caused } \\
\text { by gluing effects }\end{array}$ & ----- & $9.88 \mathrm{~s}$ & $3.95 \mathrm{~s}$ \\
\hline
\end{tabular}

Fig. 9 shows the total saturation in the inhomogeneous Ultra napkin during the second wetting. Yellow represents high, red medium and blue low saturation. To enable a better insight into the layer structure, the section $\mathrm{y}=0$ was chosen. The large saturation in the granule layer at the top is due to the first wetting. Because of the absence of granules below the cylinder the liquid transport in vertical direction is not hindered, a fact that ensures small absorbtion times.

\section{b) Humidity at the Upper Surface}

While granules exhibit a negative influence on the absorbtion time their advantages become evident by considering the humidity at the surface that is in contact with the baby's skin. As a measure for the average surface humidity we define

$$
\sigma\left(t_{n}\right):=\frac{1}{N_{2} \cdot N_{3}} \sum_{j=1}^{N_{2}} \sum_{k=1}^{N_{3}} c_{c}\left(x_{1 j k}, t_{n}\right)
$$

Since the baby is not sensible of liquid inside the granules, $\sigma$ contains only concentrations in the cellulose. These concentations are averaged over the complete upper surface.

The humidity of the different napkins is compared in figure 8. After 3 hours a second wetting is simulated. Since the liquid in the granules cannot contribute to the surface humidity, the homogeneous Ultra napkin performs better than the napkin without granules. Hoverever, the inhomogeneous napkin is superiour. In its layer at the top, the large concentration of granules absorbs the major part of the fluid in the intermediate spaces. In figure 8 one observes that the inhomogeneous napkin after the second wetting is even almost as dry as a homogeneous one after the first wetting. 


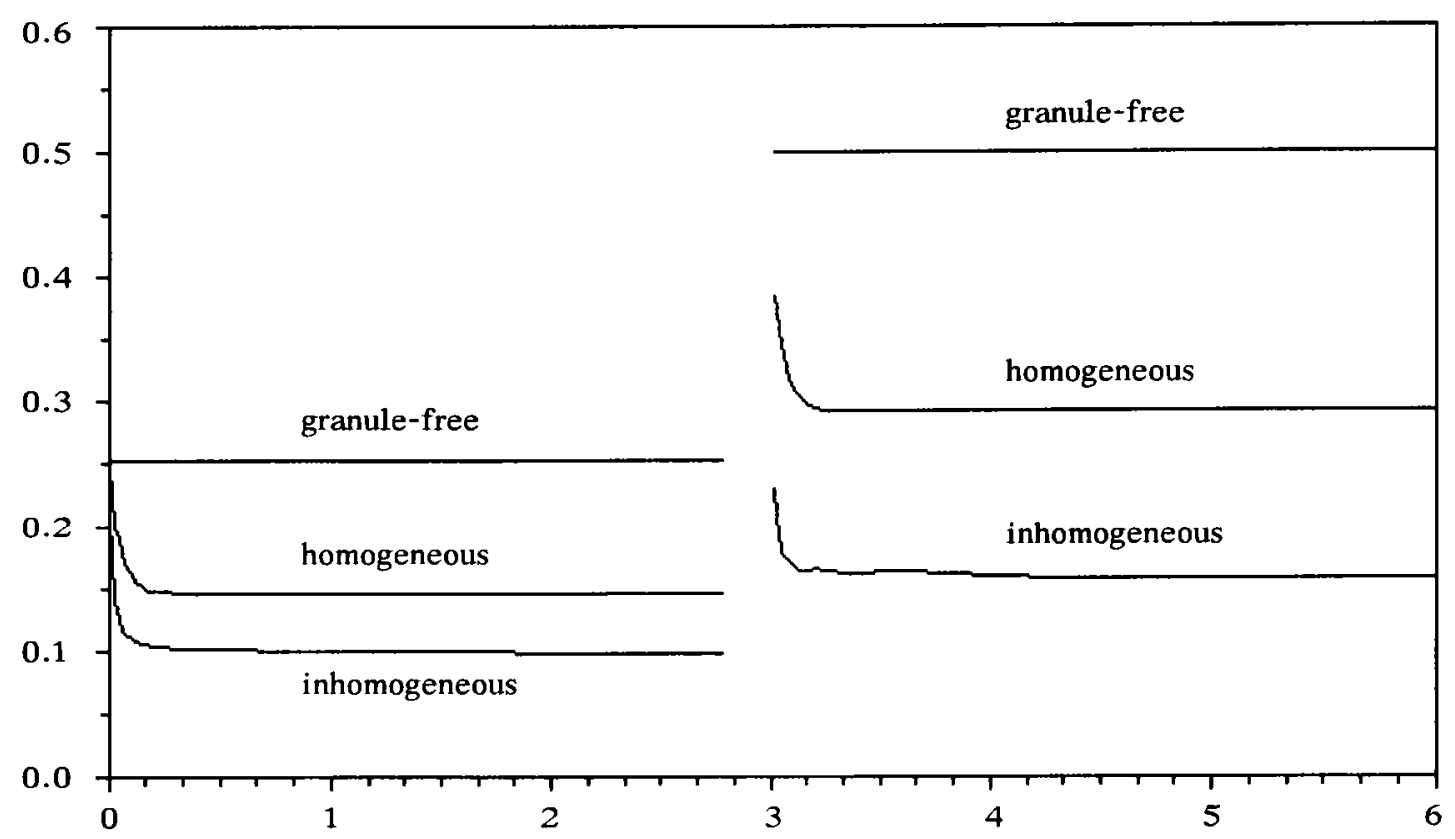

Fig. 8. Humidity $\circ\left[\mathrm{g} / \mathrm{cm}^{3}\right]$ vs. time $t[\mathrm{~h}]$

Photos of the computer simulation of the inhomogeneous Ultra napkin several minutes after the second wetting are shown in figure 10 to 12 . Although the total liquid saturation in the granule layer is very high (Figure 10), almost no fluid can be found in the ccllulose of this layer (figure 11), which means that the liquid is nearly completely absorbed by the granules and the humidity $\sigma$ is very low. Below the granule layer optimal liquid transport without gluing effects is possible.

The difference between the two types of cencentration, $\tilde{\mathrm{c}}_{\mathrm{C}}$ and $\mathrm{c}_{\mathrm{C}}$, becomes obvious by comparing figure 11 with figure 12 . Since the diffusion process is related to the intermediate space, one recognizes an equilibrium between the intermediate space saturation $\tilde{c}_{\mathrm{C}}$ in the granule layer and the layer below (figure 12). However, the intermediate space in the granule layer is very small, therefore this high saturation has almost no influence on the concentration $c_{c}$ and the baby is kept dry (figure 11). 

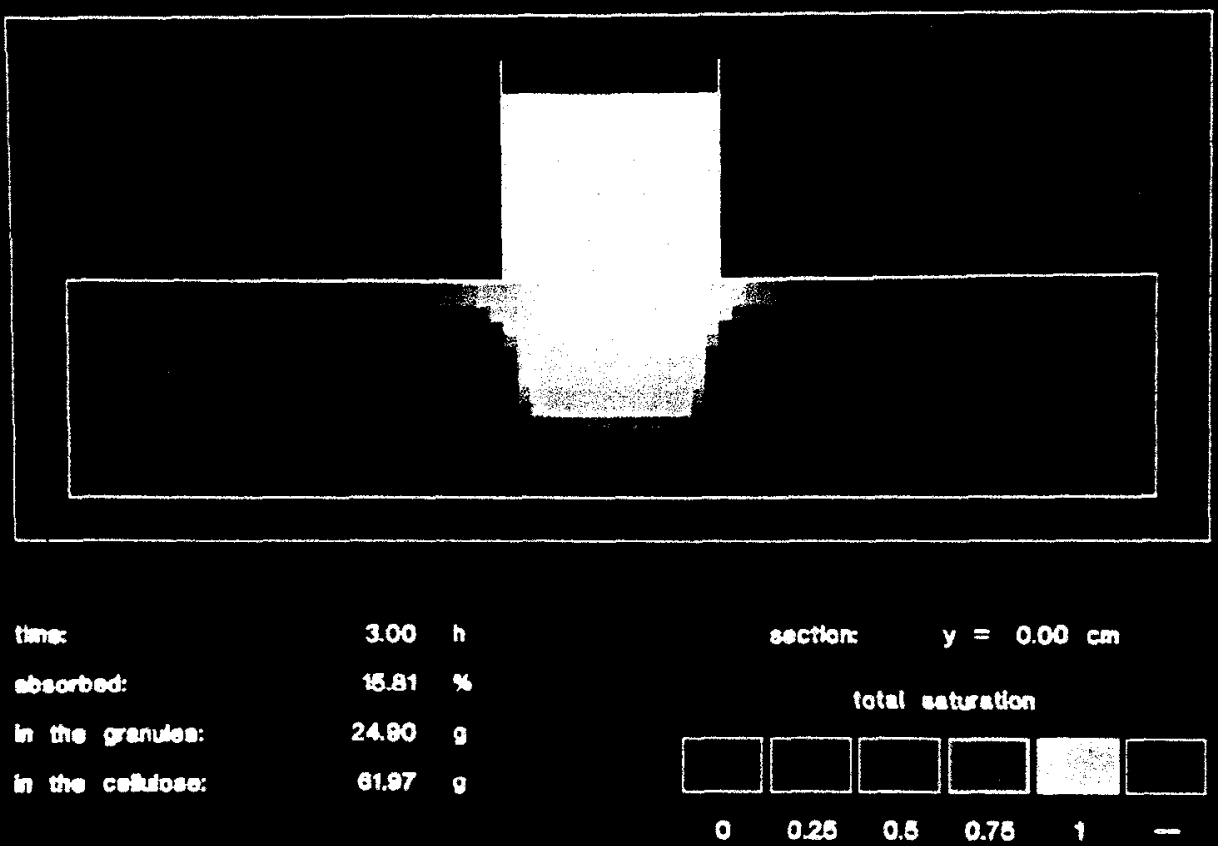

Fig. 9. Inhomogeneous Ultra napkin during the second wetting

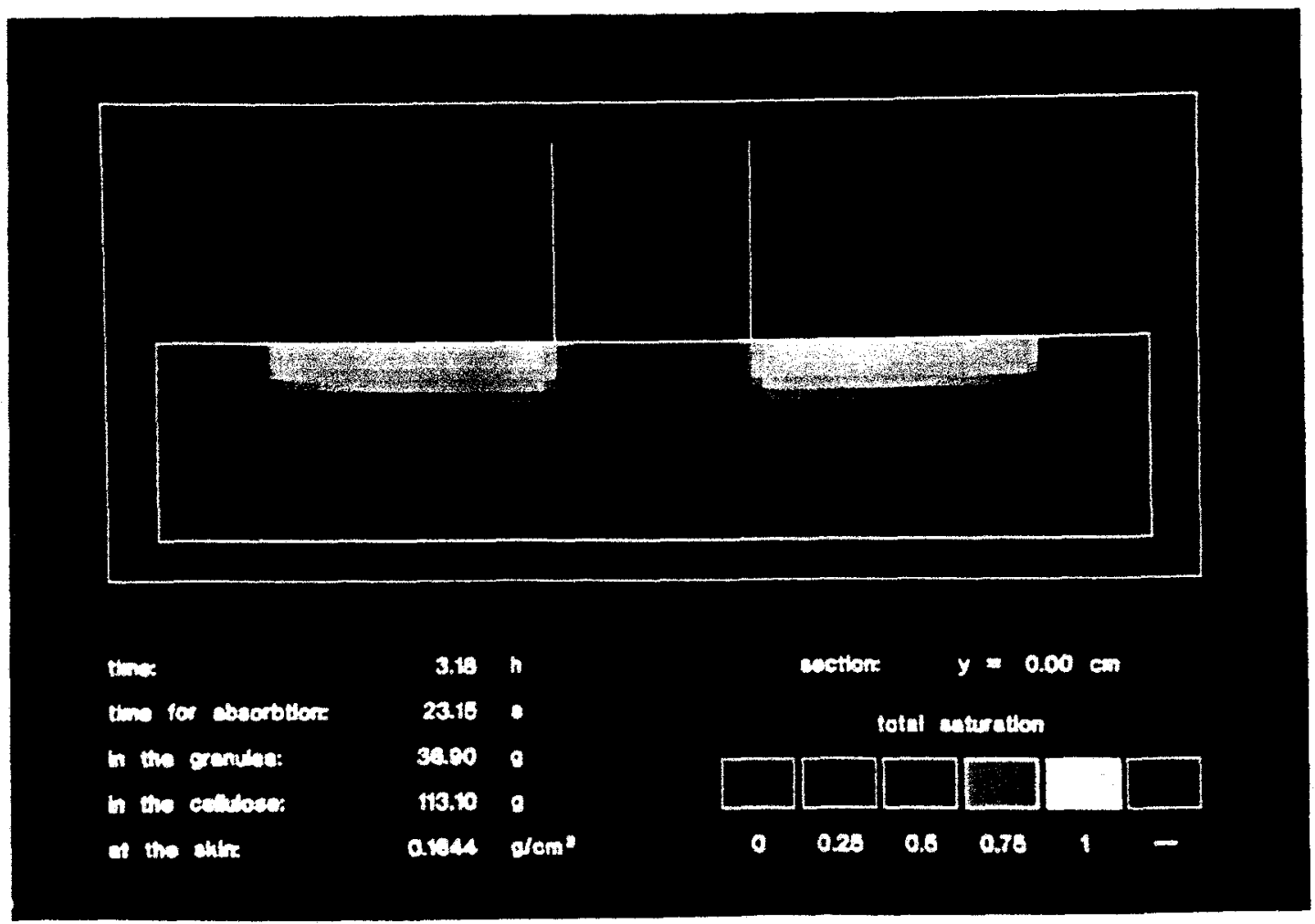

Fig. 10. Total saturation for the inhomogeneous Ultra napkin 


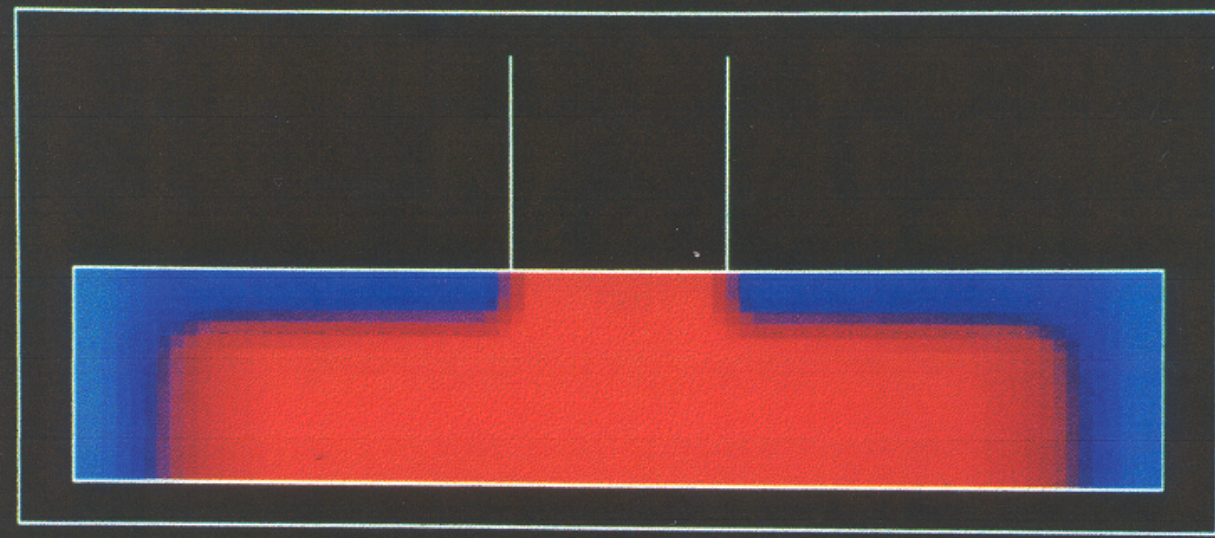

tinne:

tine for cbectotien:

in the erencilas:

in the eellinese:

at the cklix:
$3.19 h$

22150

$\sec \theta$

118.100

O.1944 dem coetlon: $\quad y=0.00 \mathrm{~cm}$

cencontration in the cellitoes

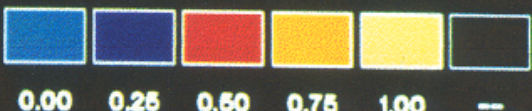

Fig. 11. Concentration $c_{c}$ for the inhomogeneous napkin

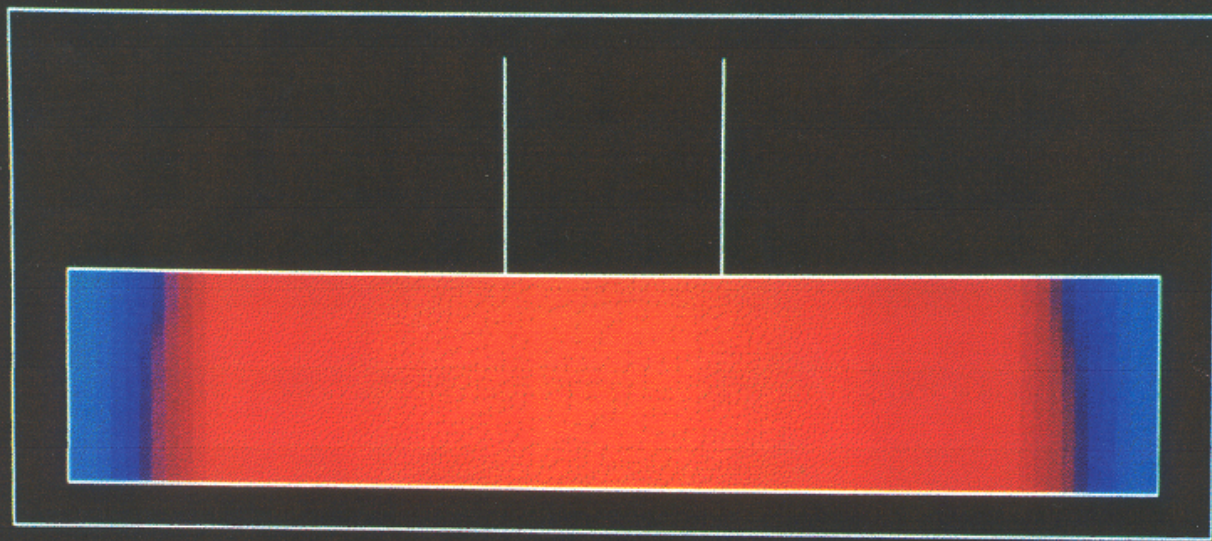

time:

time for cbectotion:

in the eranulas:

in the cellitose:

at the ckin:
$3.18 h$

$23.15 \bullet$

3800

113.109

$0.1944 \mathrm{~d} / \mathrm{cm}^{2}$ coetion: $\quad y=0.00 \mathrm{~cm}$

eaturation in the intermedilate cpaces

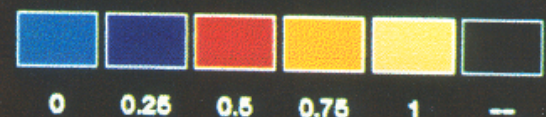

Fig. 12. Intermediate space saturation $\tilde{c}_{c}$ for the inhomogeneous napkin 


\section{SUMMARY AND CONCLUSIONS}

In this report a mathematical model for Ultra napkins was derived describing the liquid transport as a diffusion phenomenon related to the intermediate space volume of the cellulose. The diffusivity grows exponentially with the intermediate space saturation. Liquid exchange between cellulose and granules is assumed to be reversible.

The model can be implemented efficiently by using three splitting techniques: a symmetrical time splitting for the decoupling of diffusion and liquid exchange, a predictorcorrector ansatz for replacing one nonlinear system by two linear systems and an ADI scheme for splitting into implicitly one dimensional problems. The step size is controlled automatically by choosing a time step according to a stability criterion.

For realistic data the model describes the influence of the granules like gel blocking and absorbtion properties sufficiently well. Hence it can be used as an operational tool to optimize the granule distribution. The simulations show that quite simple ideas permit remarkable improvements of napkins. Hence we expect that further progress can be obtained by a more detailed analysis of suitable granule distributions.

Furthermore, applications of the present model are not only restricted to the study of appropriate granule distributions. Moreover, it can be used to investigate the influence of other parameters or it can be applied to areas similiar Ultra techniques are involved, e.g. sanitary towels.

\section{Acknowledgement}

The author thanks Prof. H. Neunzert for initiating this interesting subject and Dr. J. Fröhlich for valuable hints and fruitful discussions. 


\section{REFERENCES}

[1] 'Bei bester Laune', Chemie Journal, 2, 8-9 (1988).

[2] Crank, J. and Nicolson, P., 'A practical method for numerical evaluation of solutions of partial differential equations of the heat conduction type', Proc. Cambridge Philos. Soc., 43, 50-67 (1947).

[3] Crank, J., The Mathematics of Diffusion, Clarendon Press, Oxford, 1975.

[4] Douglas, J. jr. and Gunn, J.E., 'A general formulation of alternating direction methods. Part I. Parabolic and hyperbolic problems', Numer. Math., 6, 428-453 (1964).

[5] Douglas, J.jr. and Jones, B.F., 'On predictor-corrector methods for nonlinear parabolic differential equations', J. Soc. Ind. Appl. Math., 11, 195-204 (1963).

[6] Jost, W. and Hauffe, K., Diffusion - Methoden der Messung und Auswertung, Steinkopff, Darmstadt, 1972.

[7] Marchuk, G.I., 'Splitting and alternating direction methods', in: Ciarlet, P.G. and Lions, J.L. (ed.), Handbook of Numerical Analysis, Vol. I, Elsevier Publishers (North-Holland), Amsterdam, 203-462, 1990.

[8] Mitchell, A.R. and Griffiths, D.F., The Finite Difference Method in Partial Differential Equations, Wiley, Chichester, 1980.

[9] Schwarz, H.R., Numerische Mathematik, Teubner, Stuttgart, 1988.

「10ך Yanenko, N.N., The Method of Fractional Steps, Springer, New York, 1971. 